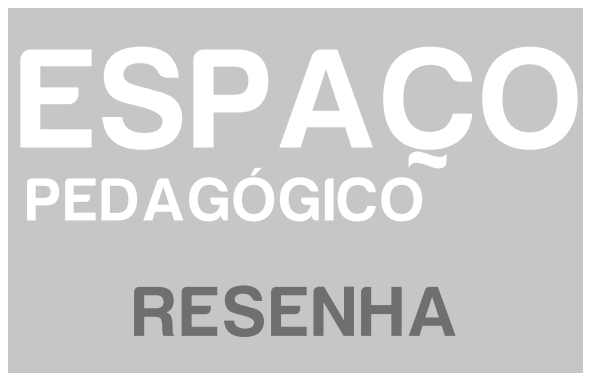




\section{Revolução digital e educação: e agora?}

Maria Augusta D'Arienzo*

A escola é fundamental como base de transformação da sociedade, preparando cidadãos com uma perspectiva comprometida com o humanitário, capazes de construir o presente e aperfeiçoar o futuro. Por isso, a leitura da obra Trabalho, educação e inteligência artificial: a era do indivíduo versátil, de Rui Fava (2018), faz com que os educadores perturbados com as revoluções proporcionadas pelos avanços das tecnologias digitais no contexto social reflitam acerca do papel e das mudanças necessárias à educação para o século XXI.

No texto, Rui Fava (2018, p. 6) define a era do indivíduo versátil como o tempo de "[...] imisção das tecnologias digitais, a robotização, a automação e a inteligência artificial no mundo do trabalho e, consequentemente, no universo da educação, que tem como propósito preparar profissionais-cidadãos para seu sucesso profissional e pessoal".

A parte 1, denominada pelo autor de Passado, presente, futuro, foi dividida em quatro capítulos. No capítulo 1, Substituição do esforço físico por instrumentos e ferramentas, Fava descreve a Revolução Agrícola usando os princípios que a caracterizam: patriarcalismo, artesanalidade, generalidade, emotividade, religiosidade, estética e nomadismo. $\mathrm{O}$ conhecimento, a cultura e as habilidades eram transmitidas aos jovens por meio da metodologia da imitação, ou seja, os aprendizes reproduziam e imitavam os mais velhos de acordo com suas práticas, costumes e hábitos. A escola contemporânea tem sua origem no final do século XVII, quando há a adoção dos processos de ensino e aprendizagem como método de educação. As modificações pelas quais a sociedade passou, da Revolução Agrícola para a Revolução Industrial, são abordadas pelo autor no capítulo 2, intitulado Substituição do trabalho físico por máquinas mecanizadas. A Revolução Industrial ocorreu nos séculos XVIII e XIX, o uso das máquinas mecanizadas levou à mudança do trabalho artesanal para o assalariado e produziu uma das maiores angústias da sociedade:

\footnotetext{
Recebido em 23/09/2018 - Aprovado em 27/02/2019

http://dx.doi.org/10.5335/rep.v26i2.9410
} 
o trabalho forçado de crianças e adolescentes. Esse movimento fez com que a escola ofertasse o ensino técnico, como forma de garantir mão de obra habilitada, treinada e disciplinada para atuar no setor manufatureiro, com o objetivo do crescimento industrial. É preciso concordar com a afirmativa do autor, de que "[...] os princípios tayloristas, a despeito de serem concebidos para o chão de fábrica, onde o trabalho físico foi substituído por máquinas mecanizadas, ainda estão fortemente arraigados no sistema escolar contemporâneo" (FAVA, 2018, p. 37).

Ao tratar da Substituição do trabalho repetitivo por máquinas "inteligentes", Fava apresenta as transformações ocorridas na passagem da Revolução Industrial para a Pós-industrial. O autor traz dois conceitos essenciais para compreender os princípios defendidos na Revolução Pós-industrial: empregabilidade, conceito que tem origem nos anos 1990 e refere-se à relação e à interdependência da empresa com seu colaborador, ou seja, "quanto ele vale no sentido de transações, mercado e aquisição de um emprego" (2018, p. 41); trabalhabilidade, que "[...] é como a pessoa se vê produzindo economicamente, relaciona-se ao know-how de gerar trabalho e/ou a versatilidade que um indivíduo possui de se ver produzindo na economia criativa, por meio de atividades com múltiplas formas de trabalho" (2018, p. 41). Então, o autor declara que "[...] a escola deve ser um sistema vivo, um conjunto de componentes que trabalha de forma homóloga, correlata, interdependente com objetivos compartilhados, e não ser uma instituição que gere apenas lucro para seus acionistas" (2018, p. 44). Enquanto o emprego era abundante, as escolas preocupavam-se em melhorar a empregabilidade de seus egressos, porém, na era em que prevalecem a inteligência artificial e a automação, o foco das instituições de ensino é sobre a trabalhabilidade, ou seja, formar empreendedores, afirma Fava.

Substituição do trabalho preditivo por automação, robotização e inteligência artificial provocando o fim do vínculo empregatício é o título eleito pelo autor para o capítulo 4. Nele, descreve a Revolução Industrial a partir de dados de pesquisas desenvolvidas na América do Norte, Europa e Ásia, considerando o futuro do trabalho e a conjuntura de metamorfose provocada pela robotização, automação e inteligência artificial. Reconhece-se como autêntico o que o autor afirma acerca da utilização das tecnologias na educação:

O comedimento necessário na adoção das tecnologias nos processos de ensino e de aprendizagem eventualmente é confundido com resistência, às vezes real, de olhar o futuro. Muitos educadores o temem, por estarem presos ao presente, ao curto prazo. Não querem predicar como será o futuro da educação, com receio, incerteza e medo da rapidez das mutações causadas na sociedade, no mercado, no mundo, por meio da IA (FAVA, 2018, p. 56). 
Fava relata os avanços da inteligência artificial em dispositivos que interagem com as pessoas e, ainda, defende que a evolução da convivência entre o ser humano e as máquinas inteligentes continuará a evoluir. Nessa perspectiva, a educação necessitará proporcionar atividades para os estudantes de maneira mais lúdica, desafiadora, relevante, criativa e investigativa, para que possam criar os seus próprios projetos e aproveitar as oportunidades do avanço das tecnologias.

A Parte 2 da obra está dividida em sete capítulos e leva o subtítulo de Disrupção singular. No capítulo 5, Papel e tinta preta versus tela digital, Fava reconta as realizações humanas relevantes na história do mundo, iniciando pela história antiga, quando a palavra falada era muito relevante, passando pelo surgimento da escrita, pela criação da prensa de Gutenberg, momento da substituição da cultura escrita pela cultura do livro, deslocando-se até a transmissão eletrônica de textos. Metamorfose tão disruptiva quanto a mudança da cultura da escrita para a cultura do livro é a transmutação da cultura do livro para a cultura das telas. $\mathrm{O}$ autor utiliza referências do historiador francês Roger Chartier para exemplificar o momento de transformação da técnica de produção e reprodução de textos, ponderando que não muda apenas o suporte de leitura, mas, também, os modos de ler. Os educadores e os processos de ensino e aprendizagem são fundamentados no texto escrito, por isso, sentem-se provocados pela fluidez da cultura da tela, diz Fava.

Realidade aumentada e realidade virtual é a designação do tema desenvolvido pelo autor no capítulo 6 , no qual se empenha em diferenciar a realidade aumentada da realidade virtual, tendo em vista que ambas pertencem ao universo da tecnologia imersiva e, por vezes, erroneamente, são tratadas como sinônimos. Para a educação, Fava diz que essas tecnologias aproximam o conteúdo à experiência dos estudantes com o mundo digital. "Eles podem desfrutar de imagens integradas à realidade tridimensional, que fogem do padrão apenas bidimensional dos objetos, como vídeos e e-books interativos" (FAVA, 2018, p. 77). Sendo assim, os conteúdos podem ser apresentados de forma a serem melhores compreendidos pelos estudantes, pois aquilo que era distante, por meio dessas tecnologias, torna-se parte da rotina dos processos de ensino e aprendizagem.

A partir do título do capítulo 7, Deuses e deusas da tecnologia, pode-se inferir que o autor fez uso da narrativa mitológica, dos mitos e das características dos deuses e deusas gregos para comparar determinadas tecnologias. Primeiramente, a partir do mito da Caixa de Pandora, refere-se à tecnologia, pois, como o mito, ela possui aspectos positivos e negativos. A descrição da evolução do acesso à internet foi assemelhada a Deméter, a deusa grega da fartura, pois o termo representa a 
eficiência, a facilidade e a velocidade de informações que o ser humano tem acesso pela rede de computadores. O processo de criação da TV foi representado por Hermes, deus da eloquência, da arte de bem falar, dos viajantes, dos negociadores, dos espertalhões, mas também dos trapaceiros e dos corruptos. A deusa Mnemosine e suas encantadoras divas foram escolhidas para significarem a diversidade dos smartphones. Ao rei dos reis, senhor do Olimpo e deus do trovão, Zeus, coube representar a poderosa inteligência artificial (IA) no Olimpo tecnológico. Baseado numa ficção tangível, Fava também apresenta a origem da IA a partir de personagens do universo real das tecnologias, como Stephen Hawking, Bill Gates e Elon Musk, os quais expressam estarem estarrecidos com a possibilidade da revolução das máquinas, pois o potencial da IA é de tornar-se mais inteligente do que qualquer ser humano. No contexto educacional, Fava reconhece que "[...] o ensino superior já vem sofrendo forte impacto sobre o perfil de formação do egresso. Mesmo em atividades especializadas, encontram-se softwares que substituem o ser humano" (2018, p. 102). O Direito é um dos exemplos, há sistema inteligente que concebe, elabora e constrói petições e recursos com mais sucesso que os advogados.

No capítulo 8, Novos paradigmas para a educação e para o trabalho, Fava identifica que a escola de massa, originada na Revolução Industrial, conserva-se até a atualidade. Considerando que, durante esse período, dois séculos, o perfil dos estudantes, a sociedade, o mercado de trabalho e a tecnologia modificaram-se, redefiniram-se e transmutaram-se, somente a escola mantém as características de sua origem. É óbvio que não basta apenas o conteúdo e a prática serem relevantes para ocorrer a aprendizagem, pois a sua efetividade se dá também pela influência da forma, da expressão facial, da postura corporal, do tom de voz, portanto, o corpo é mediador e significativo no processo de ensino. Os estudantes frequentam o ambiente escolar na busca de experiência, de encantamento, de interação com os sujeitos, da cooperação entre pares e da satisfação de se identificar como parte de um grupo.

Na sequência, o Homem Vitruviano, de Leonardo da Vinci, foi escolhido por Fava para representar o homem versátil, o qual o autor considera de vital importância para o sucesso e a manutenção da vida em tempos de inteligência artificial. A partir disso, no capítulo 9, intitulado Indivíduo versátil, o Homem Vitruviano, há a descrição das características necessárias ao indivíduo versátil em um mundo que requer interação, colaboração e participação. Indivíduos versáteis têm capacidade de adaptação, aprendizagem e crescimento constante, renovando-se em um cenário de desenfreada metamorfose. Nesse cenário, às escolas cabe a preparação de estu- 
dantes com "[...] amplitude nos braços, mobilidade, profundidade, flexibilidade nas pernas, sabendo que o conhecimento é efêmero, que as ocupações de hoje poderão não ser as mesmas de amanhã" (FAVA, 2018, p. 117). As instituições de ensino precisam se conscientizar de que os conteúdos oriundos das ciências humanas e sociais auxiliam a pensar que os indivíduos/líderes desenvolvem tarefas de caráter subjetivo, qualitativo e emocional e não apenas com matérias de natureza quantitativa e racional.

No capítulo 10, Inteligências necessárias para o século XXI, Fava destaca quatro inteligências fundamentais para o êxito profissional e pessoal no mundo digitalizado, gradativamente automatizado, robotizado, em que as funções físicas, repetitivas e preditivas estão sendo substituídas pelas criações de computação e inteligência artificial, são elas: cognitiva, emocional, volitiva e decernere. Ao término da caracterização das quatro inteligências, entende-se que as escolas necessitam implementar currículos por competência e instituir metodologias ativas que desenvolvam as quatro sapiências, com o foco na instrução de profissionais capazes de terem atitudes positivas e objetivos concretos.

Fava, de maneira objetiva, descreve, no capítulo 11, denominado $O$ iluminismo está de volta e provoca o fim da Era da Informação e o advento da Era da Experiência, que as escolas necessitam ensinar os estudantes a processar, a discernir e a escolher de modo correto as informações e transformá-las em conhecimento, pois o acesso aos conteúdos não é mais considerado um problema.

A parte 3 da obra, Futuro da educação ou educação do futuro, está subdividida em seis capítulos. O capítulo 12, Tecnologia, automação e educação, traz a discussão acerca dos seguintes questionamentos: que tipos de ofícios estão sujeitos à automação? Quais serão as competências necessárias para as novas ocupações? Como preparar estudantes para as funções que realmente existirão quando se formarem? Para problematizar as questões, o autor traz análises de pesquisas da Europa, dos Estados Unidos e do Brasil, especificamente, estatísticas do Exame Nacional de Desempenho dos Estudantes (Enade) de 2015, concluindo que o modelo educacional brasileiro está falido, pois não se harmoniza com a evolução tecnológica, o desenvolvimento do mercado e o surgimento de novas profissões.

A Educação no mundo contemporâneo é a reflexão proporcionada pelo autor no capítulo 13. Enquanto os países desenvolvidos tratam a educação com seriedade, o Brasil trabalha em oposição ao avanço da automação, perde competitividade, distancia-se dos benefícios que a tecnologia proporciona à inovação dos processos de ensino e aprendizagem. Utilizando exemplos de educação de países como Ale- 
manha, Finlândia e Reino Unido, o autor discute e propõe um modelo de currículo que pense no futuro, “[...] aprender com jovens, não de idade, mas de espírito, e não mais com os mais velhos que não estão acompanhando a metamorfose promovida pela inteligência artificial" (FAVA, 2018, p. 144-145). Os objetivos, os princípios e os propósitos do currículo devem ser estabelecidos pela tecnologia, pelo futuro e pelos jovens, criando um currículo educacional flexível, adaptável e por competências comportamentais, humanas e técnicas. Esse currículo propiciará conteúdos, materiais didáticos, tecnologias e metodologias ativas.

Na sequência, no capítulo 14, Aprendizagem ativa e experimental, Fava redige sobre a aprendizagem, destacando que ela é um tema complexo, múltiplo, heterogêneo, o que dificulta delimitá-la. $\mathrm{O}$ autor apresenta as perspectivas da taxonomia da aprendizagem ativa e experimental, ou seja, conhecimento, discernimento, análise, compreensão, aplicação e avaliação, detalhando cada uma a partir dos processos de ensino e aprendizagem, e afirma que, "[...] para atingir o estrato aplicação, é preciso dominar o discernimento e a análise da escolha, bem como a compreensão dos conhecimentos a serem adquiridos" (2018, p. 151, grifo do autor). Conclui que a educação é plural, ou seja, para cada conteúdo, habilidade e/ou competência desenvolvido, há várias estratégias de aprendizagem ativa. Nesse sentido, expõe alguns exemplos, como: Peer Instruction; Think-Pair-Share; Turn and Talk; Polling.

Dando continuidade ao tema da aprendizagem, no capítulo 15, Currículo por competências, Rui Fava relata que estudos mostram a exigência de indivíduos versáteis, que apresentam como características o pensamento divergente, a produção de ideias, a pró-atividade, a flexibilidade e a originalidade. Para tanto, os currículos precisam privilegiar o desenvolvimento das quatro inteligências citadas no capítulo 10 e tornar a sala de aula dinâmica, aberta, fluida, com foco no ensino de hábitos de mentes reflexivas. $\mathrm{O}$ autor afirma que os currículos por competências são mais apropriados, por serem "[...] flexíveis, adaptáveis, desenvolvem conceitos, procedimentos, atitudes, pensamento crítico e criatividade, tão necessários no mundo no qual as ocupações físicas, repetitivas e preditivas estão sendo realizadas por automação, robotização e máquinas munidas de inteligência artificial" (FAVA, 2018, p. 166).

Competências atitudinais na educação 3.0 é a designação e o tema escolhido por Fava para o capítulo 16. Cooperação, resiliência, ética e liderança são as competências atitudinais que, na visão do autor, deverão integrar a relação de objetivos educacionais das escolas contemporâneas. Finalizando a obra, o capítulo 17 recebe um questionamento: Como será a educação superior na próxima década? 
Nele, Fava faz uma retomada dos elementos apresentados na parte três da obra e afirma que as mudanças pelas quais passarão os currículos, consequência das tecnologias digitais e da inteligência artificial, promoverão uma singularidade na educação. $\mathrm{O}$ autor sugere o PDCA Acadêmico, citado em sua obra Educação 3.0: aplicando o PDCA nas instituições de ensino, de 2015, e explica que esse modelo é uma adaptação do PDCA proposto por Walter Andrew Shewhart, no qual P - de Plan - descreve o que e por que ensinar; D - de Do -, como ensinar; C - de Check -, modalidade ofertadas; A -de Act -, avaliação de todos os processos. Conforme Fava, o PDCA Acadêmico possui as seguintes etapas: planejamento, organização curricular, avaliação, disponibilização e distribuição.

"A Era da Inteligência Artificial proporcionará uma transição disruptiva, portentosa e impactante na educação com respeito à escolha, à organização, à disponibilização, à distribuição e à avaliação do processo de ensino e de aprendizagem" (FAVA, 2018, p. 4). Essa metamorfose é inevitável, portanto, ser expectador é um equívoco, mas a tecnologia sem intermediário não é o primordial disruptor, o essencial é compreender as necessidades e a visão do stakeholder, ou seja, da pessoa ou do grupo que tem interesse. Então, à educação é vital evoluir, valorizando as demandas do perfil de estudantes e do contexto contemporâneo, pois os robôs não substituirão os docentes integralmente, mas auxiliarão a aprimorar o desenvolvimento dos processos de ensino e aprendizagem.

A obra é complementada pelas ilustrações de Leonardo Davi de Souza Neves e integra a série Desafios da Educação. Rui Fava é formado em Administração e Ciências Contábeis, doutor em Ciências da Educação pela Universidad Católica de Santa Fé, Argentina. Atualmente, é reitor da Universidade de Cuiabá (UNIC), vice-presidente da Kroton Educacional e sócio-fundador da Atmã Educar.

\section{Referência}

FAVA, Rui. Trabalho, educação e inteligência artificial: a era do indivíduo versátil. Porto Alegre: Penso, 2018. 